\title{
Adrenal gland metastasis - an unusual manifestation of cancer cervix
}

\author{
Deenadayalan Theivasikamani, Lakshminarasimhan Srinivasan*, \\ Ramkumar Bakthavachalam
}

Department of Medical Oncology, Institute of Obstetrics and Gynaecology, Madras Medical College, Chennai, Tamil Nadu, India

Received: 28 June 2017

Accepted: 25 July 2017

\section{*Correspondence:}

Dr. Lakshminarasimhan Srinivasan,

E-mail: drnarasimhan@rediffmail.com

Copyright: (c) the author(s), publisher and licensee Medip Academy. This is an open-access article distributed under the terms of the Creative Commons Attribution Non-Commercial License, which permits unrestricted non-commercial use, distribution, and reproduction in any medium, provided the original work is properly cited.

\begin{abstract}
Cancer Cervix is the most common women related cancer in India. It mainly affects middle aged female of 40-55 years age group, largely attributed to HPV infection. Advances in radiation therapy, surgical techniques and chemotherapy, have resulted in improved survival rates. Still 20-30\% patients with cancer cervix would develop recurrent or persistent disease. Although the typical manifestations of recurrent cervical carcinoma are pelvic masses and lymphadenopathy, less typical manifestations like solid organ metastases and peritoneal carcinomatosis also can occur. The increasing prevalence of these less typical manifestations is partially related to the use of intensive pelvic radiation therapy, resulting in a shift away from pelvic recurrence toward distant metastasis, as well as related to improvements in cross-sectional imaging techniques. This article describes a clinical case of a 40-year-old patient with cancer cervix, who achieved complete remission with concurrent chemo radiotherapy and 3 years later, she relapsed with adrenal metastasis.
\end{abstract}

Keywords: Adrenal metastasis, Cancer Cervix, Chemotherapy, Radiotherapy, Relapse

\section{INTRODUCTION}

Worldwide Cancer Cervix is the second most common cancer in women, next only to breast cancer. ${ }^{1}$ In India, it is the most common woman-related cancer, followed by breast cancer. ${ }^{2}$ Every year cervical cancer is diagnosed in about 5,00,000 women globally and is responsible for more than 2,80,000 deaths annually. Current estimates indicate that in India every year $1,22,844$ women are diagnosed with cervical cancer and 67,477 dies from the disease. ${ }^{3}$ The cancer mostly affects middle- aged women (between 40 and 55 years), especially those from the lower economic status who fail to carry out regular health check-ups due to financial inadequacy. About $5.0 \%$ of women in the general population are estimated to harbour cervical HPV-16/18 infection at a given time, and 83.2\% of invasive cervical cancers are attributed to HPV16 or 18. ${ }^{4}$ There has been a regular campaign against cervical cancer for 30 years in India, but this has had little impact on the morbidity and mortality from the disease, with India ranking fourth worldwide. In urban areas, cancer of the cervix accounts for over $40 \%$ of cancers while in rural areas it accounts for $65 \%$ of cancers as per the information from the cancer registry in Barshi, India. Among Population based cancer registries (PBCR), Barshi and Chennai PBCRs had always recorded the highest incidence of cervix cancer. ${ }^{2}$

Among cancer cervix patients treated with surgery or radiotherapy, 20 to $30 \%$ will have a relapse. ${ }^{5}$ The metastases in solid organs are rare when compared to pelvic recurrence. The therapeutic decision should be 
based on the general condition, the site and extent of the relapse and/or metastases and the initial treatment

In this article, a clinical case of a 40-year-old female with cancer cervix who previously acheived complete remission with concurrent chemo radiotherapy and 3 years later, relapsed with adrenal metastasis.

\section{CASE REPORT}

Table 1: Patient's adrenal hormonal profile.

\begin{tabular}{|c|c|c|}
\hline Laboratory test & Value & $\begin{array}{l}\text { Reference } \\
\text { interval }\end{array}$ \\
\hline $\begin{array}{l}\text { Plasma corticotropin } \\
\text { (ACTH) at } 8 \text { am }\end{array}$ & $550 \mathrm{pg} / \mathrm{ml}$ & $10-60 \mathrm{pg} / \mathrm{ml}$ \\
\hline Serum Cortisol at 8 am & $<0.5 \mathrm{mcg} / \mathrm{dl}$ & $10-20 \mathrm{mcg} / \mathrm{dl}$ \\
\hline $\begin{array}{l}\text { Serum } \\
\text { Dehydroepiandrosterone } \\
\text { sulfate }\end{array}$ & $<1.0 \mathrm{mcg} / \mathrm{dl}$ & $\begin{array}{l}32-240 \\
\mathrm{mcg} / \mathrm{dl}\end{array}$ \\
\hline
\end{tabular}

A 40-year premenopausal lady Mrs. X presented in Nov 2013 with complaints of white discharge per vaginum for 3 months. She is a non-vegetarian, didn't have any co morbidities, Obstetric wise P2L2.

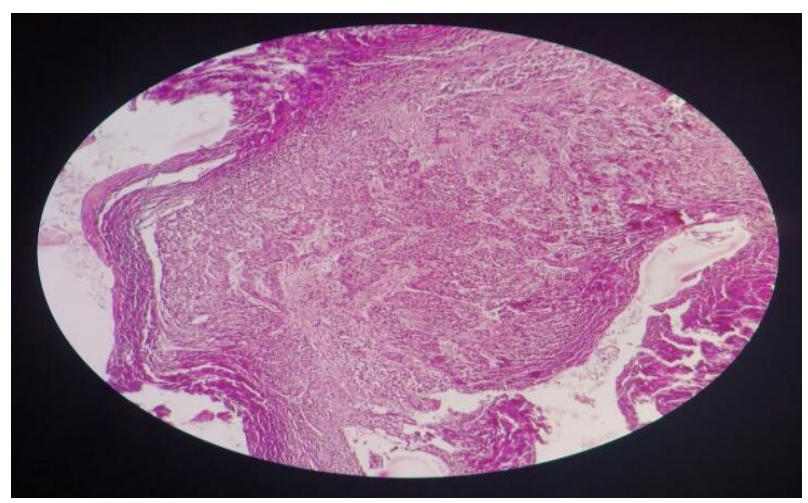

Figure 1: Cervix biopsy (H and E) low power view showing sheets and nests of poorly differentiated malignant squamous cells.

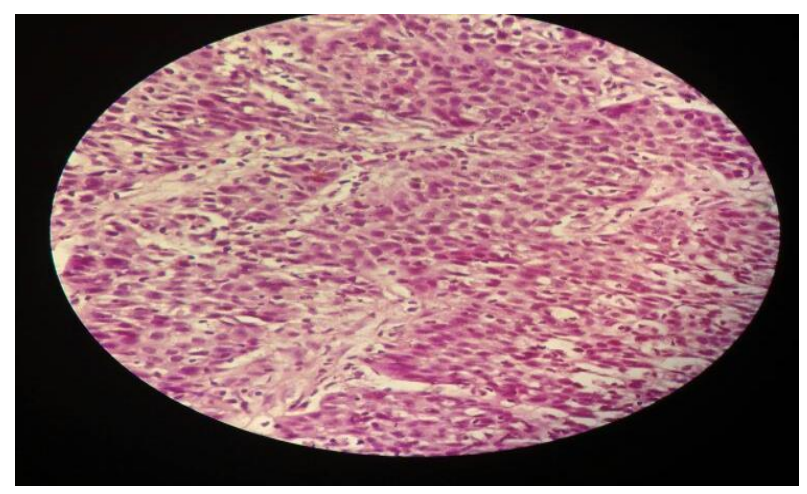

Figure 2: Cervix biopsy ( $\mathrm{H}$ and $\mathrm{E}$ ) high power view showing round to polygonal cells with moderate eosinophilic cytoplasm with round pleomorphic hyperchromatic nuclei.
On clinical examination, her general condition was fair, systemic examination was normal except per vaginum and per rectal examination which showed an ulcero proliferative growth of $5 \times 5 \mathrm{~cm}$ with medial $1 / 3$ of left parametrial involvement. Biopsy from the cervix growth showed poorly differentiated infiltrating squamous cell carcinoma.

(Figure 1 and Figure 2) USG Abdomen and Pelvis showed mass, confined to cervix. Chest X-ray and Cystoscopy were normal. The patient was staged as FIGO Stage IIB. After relevant blood investigations, patient was started with Concurrent Chemo Radiotherapy, 50Gy in 28 fractions along with 6 cycles of weekly Cisplatin from December 2013 to January 2014. Post treatment Contrast enhancing CT scan(CECT) of abdomen and pelvis showed no residual disease in cervix as well as in parametrium and no evidence of disease in the abdomen.

After the completion of the treatment the patient was on regular follow up with monthly USG abdomen and pelvis for next one year then she was on once in 3 monthly follow up in 2015. When she was reviewed in December 2016, though she was asymptomatic, her USG Abdomen and Pelvis showed a hypoechoic area of 6.4 X $5.4 \mathrm{~cm}$ below right diaphragm at anatomic adrenal area. CECT abdomen and pelvis, showed a well-defined solitary non calcified heterogeneously enhancing solid lesion in right adrenal gland with size of $5.9 \times 5.8 \times 4.1 \mathrm{~cm}$ (Figure 3 ).

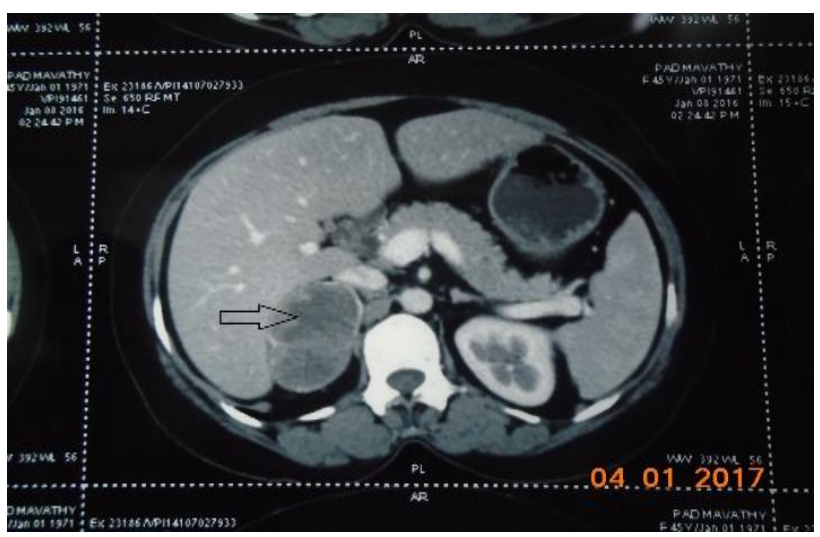

Figure 3: Heterogenously enhancing non-calcified solid lesion in right adrenal gland (January 2016).

There was no evidence of disease in other parts of abdomen and pelvis including uterine cervix. Patient was referred for surgical management. Right adrenalectomy was done in March 2016. Postoperative histo pathological examination was consistent with metastatic carcinomatous deposits from cervical primary. Repeat CECT Abdomen and Pelvis done in June 2016 showed no evidence of disease in abdomen as well as in pelvis. Thereafter patient was on regular monthly follow up. In Nov-2016 she complained of generalised weakness and increased pigmentation of body (Figure 4 and Figure 5). 


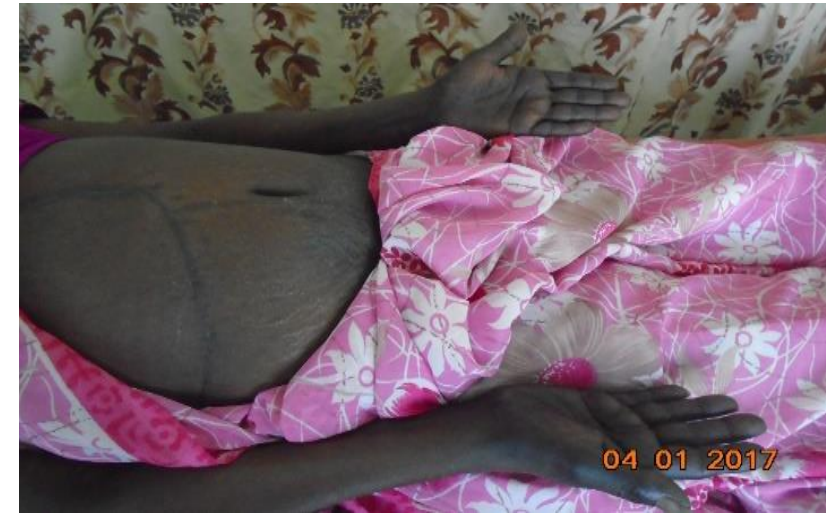

Figure 4: Right adrenalectomy scar with generalised hyper pigmentation as part of primary adrenalin sufficiency (Addison's disease).

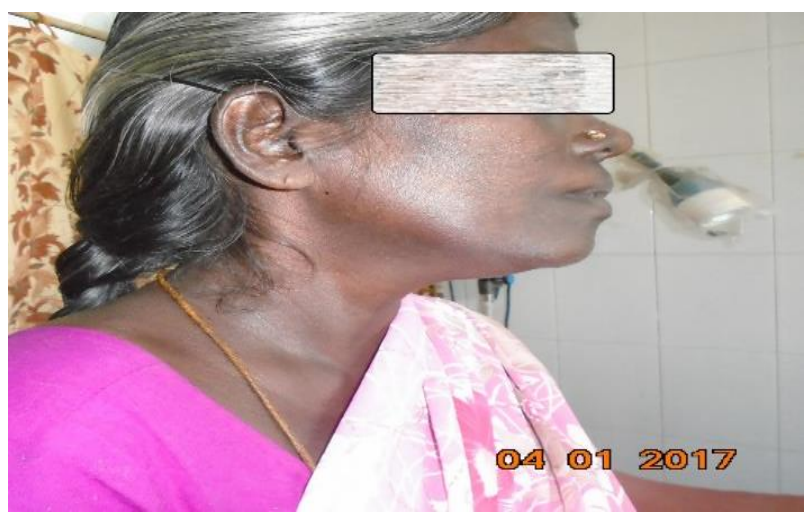

Figure 5: Hyper pigmented face as part of primary adrenal insufficiency (Addison's disease).

She was diagnosed as primary adrenal insufficiency (Addison's disease) by endocrinologist with relevant blood investigations (Table 1) and she was started with steroids. She was advised to take CECT-abdomen in Jan 2017, which showed evidence of left adrenal metastasis, left renal vein thrombosis, multiple intra-abdominal lymphadenopathy, minimal ascites, bilateral pleural effusion and minimal pericardial effusion with no abnormality in uterine cervix (Figure 6 and Figure 7).

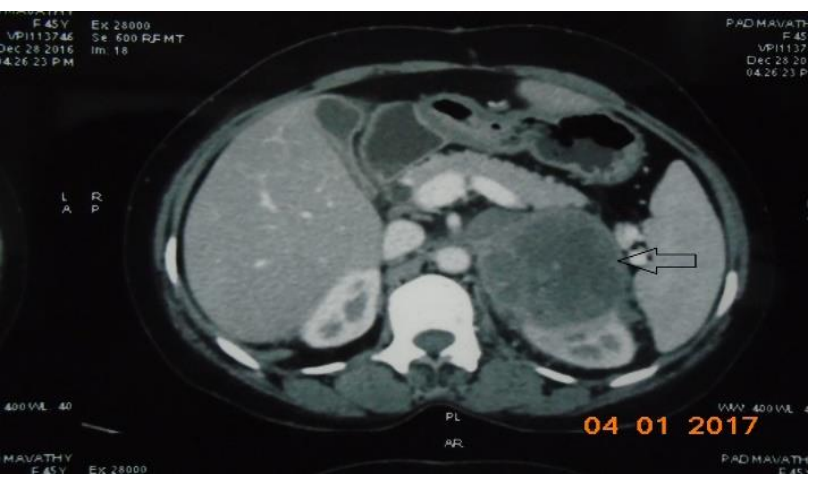

Figure 6: Left Adrenal mass lesion with left Renal vein thrombosis in cross section (January 2017).

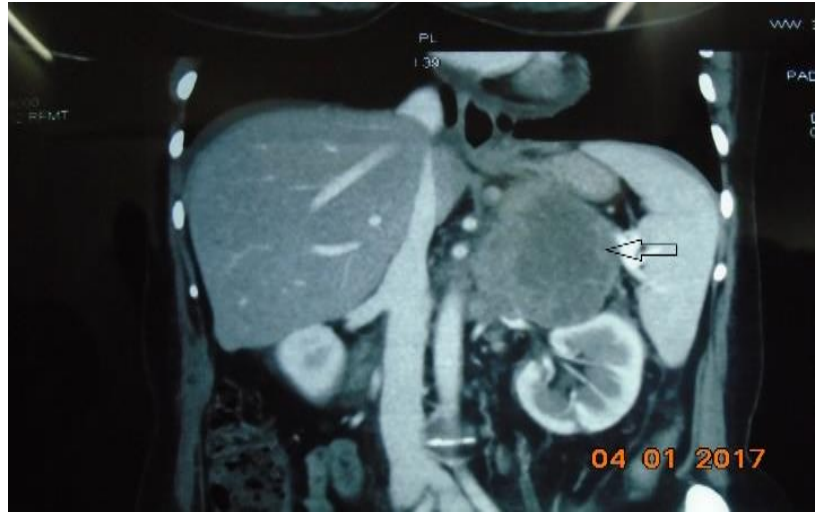

Figure 7: Left adrenal mass lesion with left renal vein thrombosis in coronal section (January 2017).

At this time, her general condition deteriorated. Further surgical management and palliative chemotherapy was deferred. She is at present on palliative and supportive care.

\section{DISCUSSION}

Cancer cervix will relapse in 20 - 30\% of patients despite advances in surgical techniques, radiation therapy and chemotherapy. Recurrence is defined as local tumor regrowth or the development of distant metastasis discovered 6 months or more after complete regression of the treated lesion. ${ }^{6}$

For cancer cervix patients, who underwent curative-intent therapy, common site of disease recurrence is local i.e. at vaginal apex or regional i.e. pelvic side wall followed by distant sites. ${ }^{7}$ Median time to recurrence in cancer cervix is 7 to 36 months after the primary treatment. The distant metastases due to recurrent disease are commonly seen in para aortic nodes (62\%), liver (33\%), lung (33 to $38 \%$ ), peritoneum (5 to $27 \%$ ), adrenal gland (14 to $16 \%$ ), intestines $(12 \%)$ and skin $(10 \%)$. Rarely, the pericardium and myocardium may be involved. Large necrotic psoas metastases that simulate abscesses have also been reported in women infected with human immunodeficiency virus. ${ }^{7}$ Osseous lesions usually occur secondary to direct extension from adjacent nodes and most commonly involve the lumbar spine. The spleen, pancreas, and kidneys are rarely involved by recurrent tumor.

Metastatic involvement of the adrenal glands due to gynaecological neoplasms especially due to carcinoma cervix is a relatively rare condition. Some cases of adrenal metastases were reported with cervical adenocarcinomas. $^{8}$

Treatment of metastatic disease is based on the general condition, the site and extent of the relapse and/or metastases and the initial treatment. ${ }^{9,10}$ The limited disease needs local therapy i.e. surgery or radiotherapy 
with curative intent. Extensive disease needs chemotherapy, if patient general condition permits. ${ }^{11-13}$

\section{CONCLUSION}

Cancer cervix is the leading cause of gynaecological morbidity and mortality in India. Despite advances in primary treatment, significant proportion of the affected patients can relapse later. Intensive pelvic radiotherapy and improved radiographic techniques result in shifting of recurrences from pelvis to distant sites. The treatment for patients with relapsed cervical cancer will depend on the patient general condition, the site of the relapse and the initial treatment. This patient developed metastatic disease even after adrenalectomy. Hence, she was put on palliative care.

Funding: No funding sources Conflict of interest: None declared

Ethical approval: Not required

\section{REFERENCES}

1. Ries LAG, Harkins D, Krapcho M. SEER Cancer Statistics Review, 1975 to 2003. National Cancer Institute, Bethesda, MD; 2006. Available at https://seer.cancer.gov/archive/csr/1975_2003/results _merged/sect_05_cervix_uteri.pdf

2. National Cancer Registry Programme (NCRP, ICMR). Time trends in cancer incidence rates:19822005. Bangalore: NCRP; 2009. Available at http://ncrpindia.org/Annual_Reports.aspx

3. Nandakumar, Ramnath T, Chaturvedi M. The magnitude of cancer cervix in India National Cancer Registry Programme (ICMR), Bangalore, India; 2009. Available at http://medind.nic.in/iby/t09/i9/ibyt09i9p219.pdf

4. ICO Information Centre on HPV and Cancer India Human Papillomavirus and Related Cancers, Fact Sheet; 2017. Available at http://www.hpvcentre.net/statistics/reports/IND_FS.p df
5. Burghardt E, Baltzer J, Tulusan AH, Haas J. Results of surgical treatment of 1028 cervical cancers studied with volumetry. Cancer. 1992;70(3):648-55.

6. Ann S. Fulcher, Susan G. O'Sullivan, Eileen M. Segreti, Brian D. Kavanagh. Recurrent Cervical Carcinoma: Typical and Atypical Manifestations RSNA Radiographics; 1999.

7. Straughn JM. Invasive cervical cancer: Patterns of recurrence and posttreatment surveillance. Available at http://www.uptodate.com/contents/invasivecervical-cancer-patterns-of-recurrence-andposttreatment-surveillance

8. Baron M, Hamou L, Laberge S, Callonnec F, Tielmans A, Dessogne P. Metastatic spread of gynaecological neoplasms to the adrenal gland: case reports with a review of the literature Eur J Gynaecol Oncol. 2008;29(5):523-6.

9. Friedlander M, Grogan M. U. S. Preventative Services Task Force. Guidelines for the treatment of recurrent and metastatic cervical cancer. Oncologist. 2002;7:342.

10. Gadducci A, Tana R, Cosio S, Cionini L. Treatment options in recurrent cervical cancer (Review). Oncol Lett. 2010;1(1)3-11.

11. Van Nagell JR, Rayburn W, Donaldson ES, Hanson M, Gay EC, Yoneda J, et al. Therapeutic implications of patterns of recurrence in cancer of the uterine cervix. Cancer. 1979;44(6):2354-61.

12. Leitao MM, Chi DS. Recurrent cervical cancer. Curr trat Options Oncol. 2002;3(2):105-11.

13. Kamura T, Ushijima K. Chemotherapy for advanced or recurrent cervical cancer; Taiwanese. J Obstet Gynecol. 2013;23

Cite this article as: Theivasikamani $\mathrm{D}$, Srinivasan $\mathrm{L}$, Bakthavachalam R. Adrenal gland metastasis - an unusual manifestation of cancer cervix. Int J Reprod Contracept Obstet Gynecol 2017;6:4150-3. 